\title{
Nuevos datos sobre Aphodius (Aphodius) conjugatus (Panzer, 1795) (Coleoptera, Aphodiidae) en España
}

\author{
P. Rahola Fabra*
}

El material examinado para escribir esta nota procede de un viaje entomológico por España durante el mes de marzo del 1982, en el cual se observaron muchos ejemplares de Aphodius conjugatus y se capturaron algunos (8 machos y 5 hembras in Col. P. Rahola).

Esta vistosa especie es bastante escasa en España. Se ha citado de Cataluña, Logroño, Huesca, Segovia, Ávila, Madrid y de Burgos (Báguena, 1967; Baraud, 1992); su área de distribución parece limitada a la mitad norte de la península.

Las dos estaciones donde se encontró la especie, son pastos abiertos de media montaña. La primera está situada cerca del Puerto del Pico, en la Sierra de Gredos (Ávila), a una altitud de 1.350 metros; en ella, los insectos explotaban boñigas de ganado vacuno de gran tamaño y relativamente frescas. Eran muy abundantes: se observaron 48 ejemplares en un total de 11 boñigas.

La segunda se sitúa en los Montes de Toledo, cerca de Retuerta del Bullaque (Ciudad Real), a una altitud de 806 metros; en esta segunda estación, Aphodius conjugatus era muy escaso, sólo se capturo una pareja de un total de 10 boñigas investigadas.

Ambas citas se corresponden con las observaciones conocidas de esta especie, que se encuentra en medios abiertos de media montaña, sobre todo en primavera (marzo/abril) y en otoño (noviembre) (Lumaret, 1990). Es interesante subrayar que la segunda localidad mencionada está situada al sur del área de distribución conocida.

Aphodius conjugatus está distribuido por Europa central y meridional (alcanza Polonia hacia el norte), Ucrania, Turquía, Cáucaso, Turkmenistán y Asia Menor, y tiene una repartición discontinua por el sur de Europa (Baraud, 1992; Dellacasa, 1983). Su distribución esporádica y la escasez de capturas hacen que cada precisión y nuevo registro sean importantes.

\section{Referencias}

BÁguena Corella, L., 1967. Scarabaeoidea de la fauna ibero-balear y pirenaica. Instituto Español de Entomología, CSIC. Madrid. 576 pp.

BARAud, J., 1992. Coléoptères Scarabaeoidea d'Europe. Faune de France et régions limitrophes, vol. 78. Fédération française des Sociétés de Sciences Naturelles et Société Linéenne de Lyon. Paris et Lyon. $856 \mathrm{pp}$.

DellacAsA, G., 1983. Sistematica e nomenclatura degli Aphodiini italiani (Coleoptera Scarabaeidae: Aphodiinae). Monografie I. Museo Regionale di Scienze Naturali. Torino. 464 pp.

Lumaret, J. P., 1990. Atlas des Coléoptères Scarabéides Laparosticti de France. Muséum National d' Histoire Naturelle; Inventaires de Faune et de Flore, fascicule 1; Secrétariat de la Faune et de la Flore. Paris. 419 pp.
Recibido, 28-I-2004

Aceptado, 16-IV-2004

Publicado, 25-VIII-2004

*_F-30250 Junas.chrahola@wanadoo.fr 